\title{
Primary bone lymphoma of the left radius: a case report and related literature review
}

\author{
Min Liu ${ }^{1 \dagger}$, Bailong Liư ${ }^{1 \dagger}$, Fujun Han² and Yanqiu Song ${ }^{2 *}$
}

\begin{abstract}
Primary bone lymphoma (PBL) is a rare but distinct clinicopathological disease. Because it is not common, the optimal treatment strategy has not been established. Here, we present a patient with PBL of the left radius and review the related literature. We focus on the standard treatment for PBL. Many aspects such as rehabilitation, local control and overall survival need to be considered. Studies on this disease should be carried out to clarify the optimal treatment in the future.
\end{abstract}

Keywords: Bone lymphoma, Chemotherapy, Radiotherapy

\section{Background}

Primary bone lymphoma (PBL) is a distinct disease. Here, we present a patient with PBL who received combined therapy with radiotherapy, chemotherapy, surgery and rituximab. Additionally, related reports of PBL are reviewed. Further studies are needed to establish the standard strategy for PBL.

\section{Case presentation}

A 53-year-old man presented at the First Hospital of Jilin University (Changchun, China) in December 2011 with a history of progressive pain of the left wrist for about 2 months. The X-ray radiograph of the left upper extremity showed a large osteolytic lesion of the distal radius (Figure 1). The bone biopsy from another hospital revealed $\mathrm{B}$ cell non-Hodgkin lymphoma. The immunochemistry showed: LCA (+), CD20(+), BCL-2(slightly +), CD79a(-), CD3(-), CD43(-), CD56(-), CD138(-), CD38 $(-), \mathrm{k}(-), \lambda(-)$ and $\mathrm{Ki}-67(70 \%+)$. The patient then went to the tertiary hospital for consultation of the pathologic results. The definitive diagnosis was diffuse large B cell lymphoma, derived from active B cells out of the germinal center. The immunochemistry revealed: CD10(-), BCL6(+), MUM-1(+), CD5(-) and cyclin D1(-). Positron emission tomography-computed tomography (PET/CT)

\footnotetext{
* Correspondence: lijie200461@126.com

${ }^{\dagger}$ Equal contributors

${ }^{2}$ Cancer Center, The First Hospital, Jilin University, 71 Xinmin Street, Changchun 130021, China

Full list of author information is available at the end of the article
}

suggested that there was extremely intense focal uptake in the distal left radius and no focal uptake in other sites (Figure 2). The patient did not have fever, night sweats, pruritus or weight loss.

Laboratory investigations demonstrated a normal complete blood cell count and a generally normal serum biochemical profile. $\beta_{2}$ microglobulin was $2.30 \mathrm{mg} / \mathrm{L}$. Erythrocyte sedimentation rate was $17 \mathrm{~mm} / \mathrm{h}$. Lactate dehydrogenase was normal. The bone marrow aspiration did not find neoplastic involvement. Thus, a primary bone lymphoma, Ann Arbor stage I, International Prognostic Index score 0, was diagnosed.

First, the patient received radiotherapy. When the dose reached $28 \mathrm{~Gy} / 14 \mathrm{f}$, we gave a cycle of concurrent chemotherapy of rituximab, cyclophosphamide, vincristine and prednisone (R-COP), and the fraction dose was reduced to $1.5 \mathrm{~Gy}$. The total dose was $28 \mathrm{~Gy} / 14 \mathrm{f}$ plus $12 \mathrm{~Gy} / 8 \mathrm{f}$. The patient then received a cycle of single rituximab. On 1 February 2012, surgery was performed to remove the tumor at the distal region of the left radius, and autograft of the fibula was done and then internally fixed. Thirty radioactive iodines were implanted into the primary tumor bed during the surgery. The postoperative PET-CT did not find any intensive focal uptake. The patient then received a cycle of single rituximab, rituximab, cyclophosphamide, doxorubicin, vincristine and prednisone (R-CHOP) and CHOP, respectively. To date, the patient's condition remains stable and diseasefree survival (DFS) has reached nearly 2 years. 


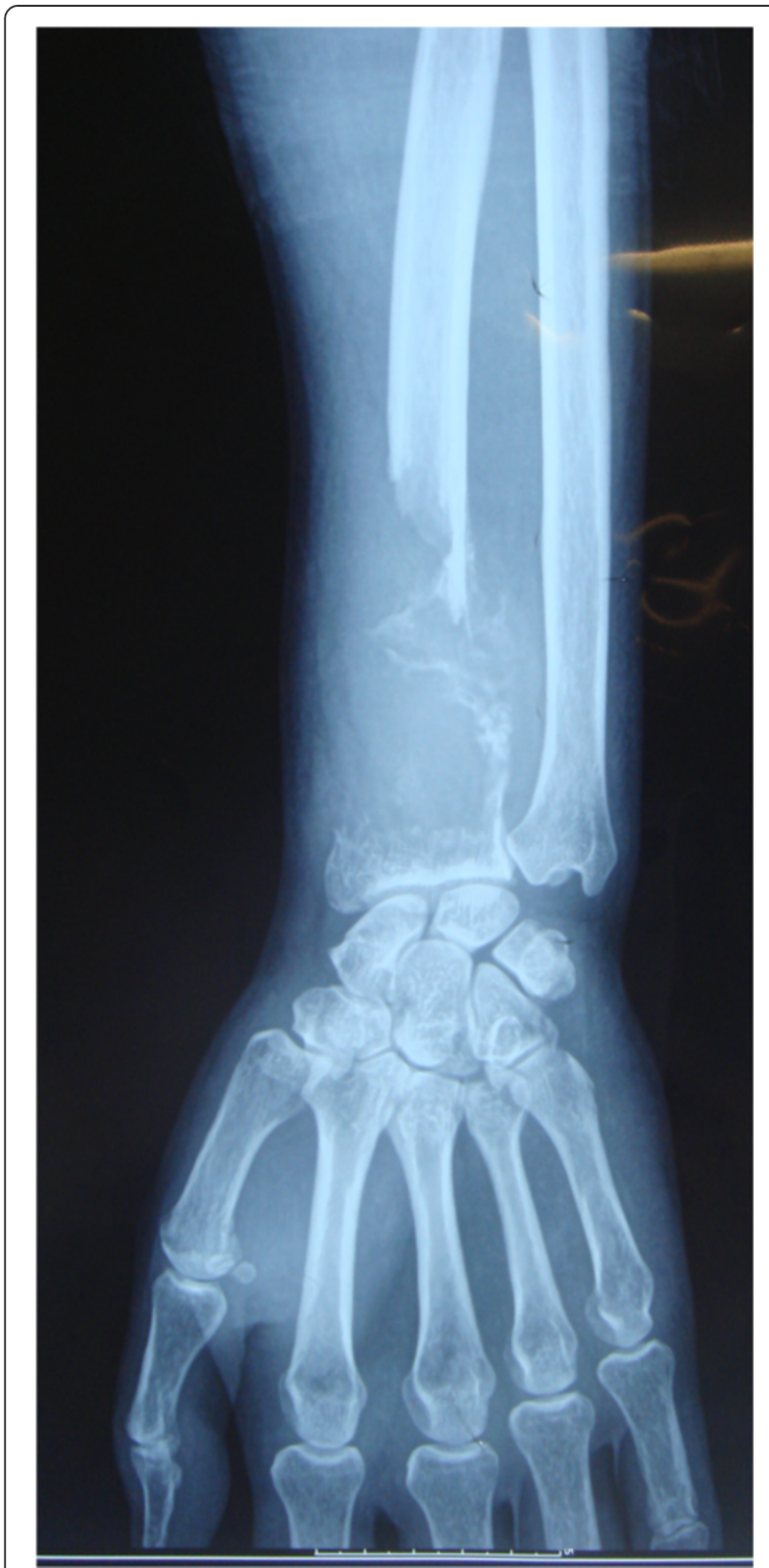

Figure $1 \mathrm{X}$-ray radiograph showed a large osteolytic lesion of the distal region of the left radius.

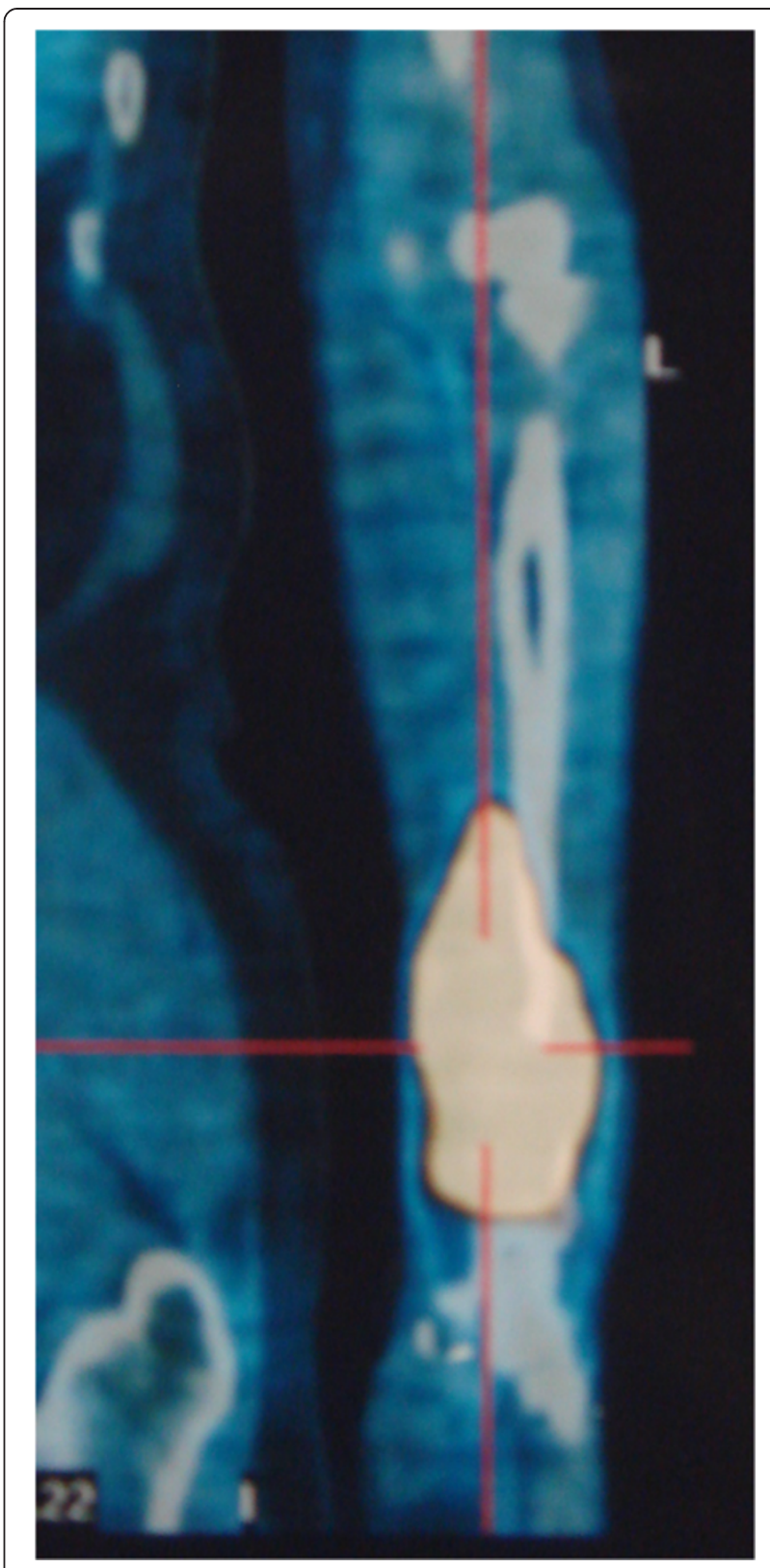

Figure 2 Pre-therapeutic PET/CT showed intensive FDG uptake in the distal region of the left radius. FDG, fluorodeoxyglucose; $\mathrm{PET} / \mathrm{CT}$, positron emission tomography-computed tomography.

[3-7]. The most frequent sites of involvement in PBL are the vertebra, pelvis, femur, humerus, skull and rib [3]. Common clinical manifestations include local pain and swelling [1].

Ford et al. showed that combined modality treatment (CMT) provided both disease control and survival benefits for PBL compared with single treatment [8]. However, the role of radiotherapy for advanced PBL was challenged in a report by Ramadan et al. [3]. The addition of radiotherapy to chemotherapy for advanced cases reduced the pathological type, accounting for about $80 \%$ of PBLs 
10-year overall survival from $56 \%$ to $25 \%$. Whether CMT should be the standard option for PBL requires more research. Achemlal et al. reported a case in which rituximab resulted in remarkable improvement for a chemo-resistant PBL [9]. Ramadan et al. insisted that irradiation should be carried out when spinal cord compression or residual tumor after chemotherapy existed, which seemed that irradiation only played a minor role [3]. On the contrary, a prospective trial emphasized the importance of radiotherapy to improve the local control and recommended a higher dose (40 to $45 \mathrm{~Gy}$ ) than that for other types of lymphoma [10]. A retrospective, multicenter Rare Cancer Network (RCN) study also presented a good outcome offered by chemoradiotherapy for early stage of PBL [11]. For a case of PBL of the left mandible, Bosch-Barrera et al. reported that chemotherapy (R-CHOP) plus consolidate radiotherapy can result in tumor-free survival of 28 months [12].

Orthopedic intervention is usually needed for pathologic fractures, avascular necrosis, spinal cord compression, or for lesions of the weight-bearing bones compromising stability or joint motion. The potential for long-term survival suggests the use of implants and techniques that have the best chance of long-term control [13]. In our case, concurrent radiotherapy and chemotherapy were given to rapidly eliminate the tumor. However, pathological fracture did happen and we had to remove the tumor surgically. Autograft of the fibula was done and then internally fixed.

PBL has a favorable prognosis over patients of systemic lymphoma with bone involvement. Age is a prognostic factor. The majority of the reports indicate better survival for patients younger than 60 years, but there are a few other reports that show better survival in patients younger than 40 or 50 years [4]. Jawad et al. analyzed 1,500 adult patients with $\mathrm{PBL}$, and pointed out that younger age and localized disease were independent predictors of survival [14]. The study also noted that the incidence of the disease has increased during recent years [14]. Future treatment for patients with PBL needs to be dependent on strict staging criteria and adherence to successful published protocols using collaborative clinical trials.

\section{Conclusion}

PBL is a rare but distinct clinicopathological entity. Compared with single treatment, CMT can result in both a good local control rate and survival benefits for local PBL.

\section{Consent}

Written informed consent was obtained from the patient for publication of this case report and accompanying images. A copy of the written consent is available for review by the Editor-in-Chief of this journal.

\section{Abbreviations}

CMT: Combined modality treatment; DFS: Disease-free survival;

FDG: Fluorodeoxyglucose; PBL: Primary bone lymphoma; R-COP: Rituximab, cyclophosphamide, vincristine, prednisone; R-CHOP: Rituximab, cyclophosphamide, doxorubicin, vincristine, prednisone.

\section{Competing interests}

The authors declare that they have no competing interests.

\section{Authors' contributions}

$M L$ was a major contributor in writing the manuscript. BL critically revised the manuscript. FH reviewed the PBL treatment. YS reviewed the literature and gave final approval of the version to be submitted. All authors read and approved the final manuscript.

\section{Authors' information}

$M L$ and $B L$ are the joint first authors.

\section{Acknowledgements}

The authors thank Guangnan Chen for revision of the medical English in the article.

\section{Author details}

'Department of Radiation Oncology, The First Hospital, Jilin University, 71 Xinmin Street, Changchun 130021, China. ${ }^{2}$ Cancer Center, The First Hospital, Jilin University, 71 Xinmin Street, Changchun 130021, China.

Received: 16 December 2013 Accepted: 31 March 2014

Published: 9 April 2014

\section{References}

1. Limb D, Dreghorn C, Murphy JK, Mannion R: Primary lymphoma of bone. Int Orthop 1994, 18:180-183.

2. Huebner-Chan D, Fernandes B, Yang G, Lim MS: An immunophenotypic and molecular study of primary large B-cell lymphoma of bone. Mod Pathol 2001, 14:1000-1007.

3. Ramadan KM, Shenkier T, Sehn LH, Gascoyne RD, Connors JM: A clinicopathological retrospective study of 131 patients with primary bone lymphoma: a population-based study of successively treated cohorts from the British Columbia Cancer Agency. Ann Oncol 2007, 18:129-135.

4. Beal $K$, Allen $L$, Yahalom J: Primary bone lymphoma: treatment results and prognostic factors with long-term follow-up of 82 patients. Cancer 2006 106:2652-2656.

5. de Camargo OP, dos Santos Machado TM, Croci AT, de Oliveira CR, Giannotti MA, Baptista AM, Caiero MT, Alves VA, Matsumoto LA: Primary bone lymphoma in 24 patients treated between 1955 and 1999. Clin Orthop Relat Res 2002, 397:271-280

6. Horsman JM, Thomas J, Hough R, Hancock BW: Primary bone lymphoma: a retrospective analysis. Int J Oncol 2006, 6:1571-1575.

7. Zinzani PL, Carrillo G, Ascani S, Barbieri E, Tani M, Paulli M, Stefoni V, Sabattini E, Alinari L, Binazzi R, Tura S, Baccarani M, Pileri SA: Primary bone lymphoma: experience with 52 patients. Haematologica 2003, 3:280-285.

8. Ford DR, Wilson D, Sothi S, Grimer R, Spooner D: Primary bone lymphoma: treatment and outcome. Clin Oncol 2007, 19:50-55.

9. Achemlal L, Mikdame M, Nouijai A, Bezza A, El Maghraoui A: Dramatical improvement of chemoresistant bone lymphoma with rituximab. Clin Rheumatol 2006, 25:394-395.

10. Christie D, Dear K, Le T, Barton M, Wirth A, Porter D, Roos D, Pratt G: Limited chemotherapy and shrinking field radiotherapy for osteolymphoma (primary bone lymphoma): results from the trans-Tasman Radiation Oncology Group 99.04 and Australasian Leukaemia and Lymphoma Group LY02 prospective trial. Int I Radiat Oncol Biol Phys 2011, 80:1164-1170.

11. Cai L, Stauder MC, Zhang YJ, Poortmans P, Li YX, Constantinou N, Thariat J, Kadish SP, Nguyen TD, Kirova YM, Ghadjar P, Weber DC, Bertran VT, Ozsahin M, Mirimanoff RO: Early-stage primary bone lymphoma: a retrospective, multicenter Rare Cancer Network (RCN) study. Int I Radiat Oncol Biol Phys 2012, 83:284-291. 
12. Bosch-Barrera J, Arbea L, García-Velloso MJ, Gil-Bazo I, García-Foncillas J, Panizo C: Primary bone lymphoma of the mandible and thyroid incidentaloma identified by 18 FDG PET/CT: a case report. Cases $J$ 2009, 2:6384

13. Demircay E, Hornicek FJ Jr, Mankin HJ, Degroot H 3rd: Malignant lymphoma of bone: a review of 119 patients. Clin Orthop Relat Res 2013, 471:2684-2690.

14. Jawad MU, Schneiderbauer MM, Min ES, Cheung MC, Koniaris LG, Scully SP: Primary lymphoma of bone in adult patients. Cancer 2010, 116:871-879.

doi:10.1186/2047-783X-19-19

Cite this article as: Liu et al:: Primary bone lymphoma of the left radius: a case report and related literature review. European Journal of Medical Research 2014 19:19.

\section{Submit your next manuscript to BioMed Central and take full advantage of:}

- Convenient online submission

- Thorough peer review

- No space constraints or color figure charges

- Immediate publication on acceptance

- Inclusion in PubMed, CAS, Scopus and Google Scholar

- Research which is freely available for redistribution 